\title{
INTRODUCCION HISTÓRICA
}

Aunque el primer trasplante hepático (TH) lo realizó el

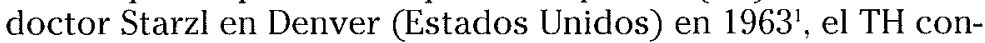
tinúa pareciendo en la actualidad un procedimiento terapéutico novedoso. Los resultados de los primeros trasplantes, por su mortalidad, fueron desalentadores. Sin embargo, la mejoría en la técnica quirúrgica, en las soluciones de preservación de órganos y en el manejo de las complicaciones postoperatorias permitió que la supervivencia al final del primer año post-TH, en los años 70 , fuera del $30 \%$. La posterior aplicación de la ciclosporina A como inmunosupresor, a finales de los años 70, duplicó dicha supervivencia. Esto permitió que en 1983 los National Institutes of Health de Estados Unidos declararan que el TH era una modalidad terapéutica que merecía una aplicación más amplia ${ }^{2}$. A partir de esta fecha han ido aumentando considerablemente tanto el número de trasplantes hepáticos como la supervivencia de los pacientes trasplantados, que al final del primer año post-TH se encuentra en la actualidad en torno al $80-90 \%$.

En España, el primer TH lo realizaron los doctores Jaurrieta y Margarit en el Hospital de Bellvitge en 1984. Desde entonces, la actividad nacional en el $\mathrm{TH}$ ha ido en aumento continuo. Actualmente tenemos casi 20 programas de $\mathrm{TH}$ y se realizan $1.000 \mathrm{TH}$ al año. La tasa anual de $25 \mathrm{TH}$ por cada millón de habitantes sitúa a España en el primer puesto mundial ${ }^{3}$.

1. Unidad de Hepatología.

2. Departamento de Cirugía General. Clínica Universitaria. Universidad de Navarra. Pamplona.
Correspondencia:

J. Ignacio Herrero

Unidad de Hepatología

Departamento de Medicina Interna

Clínica Universitaria

Avda. Pío XII, 36

31008 Pamplona

Tfno. 948296500

E-mail: iherrero@unav.es 


\section{INDICACIONES Y CONTRAINDICACIONES DEL TRASPLAN- TE HEPÁTICO}

\section{Indicaciones}

Tal como se indica en la tabla 1, existen seis grupos principales de indicaciones de TH.

El primer grupo engloba las hepatopatías crónicas. De ellas, las causas más frecuentes de TH son las hepatopatías parenquimatosas, especialmente la cirrosis etílica y la causada por el virus C, que suponen más del $70 \%$ de las indicaciones de TH. De las hepatopatías colestásicas, las más frecuentes son la cirrosis biliar primaria, la colangitis esclerosante primaria y la atresia de vías biliares (principal indicación de TH en la infancia). Las enfermedades de origen vascular (síndrome de Budd-Chiari y enfermedad veno-oclusiva) son menos frecuentemente indicación de TH.

En las enfermedades hepáticas crónicas el TH se indica cuando la supervivencia esperable sea mayor tras el TH que con la evolución espontánea de la hepatopatía, o cuando el deterioro de la calidad de vida del paciente sea muy importante. El retraso en la indicación del TH puede llevar a que el estado general del paciente en el momento del TH sea muy malo (con el consiguiente riesgo operatorio) e incluso a que el paciente fallezca antes de poder ser trasplantado. En la historia natural de la cirrosis, el pronóstico empeora notablemente tras la primera descompensación (ascitis, hemorragia digestiva varicosa, ictericia o encefalopatía $)^{4}$, por lo que debe valorarse la posibilidad del TH ante una descompensación. La clasificación de Child-Pugh, que combina cinco parámetros clínicos y de laboratorio (ascitis, encefalopatía, bilirrubina, albúmina y tiempo de protrombina) tiene una buena correlación con la supervivencia. En términos generales, se considera indicado el TH en los pacientes con una cirrosis hepática en

Tabla 1. Indicaciones de trasplante hepático.

1. Enfermedades hepáticas crónicas (cirrosis)

- Parenquimatosas

- Colestásicas

- Vasculares

2. Insuficiencia hepática aguda grave

3. Tumores hepáticos

4. Enfermedades metabólicas

- Asociadas a enfermedad hepática

- No asociadas a enfermedad hepática

5. Retrasplante

6. Miscelánea 
estadio B ó C de esta clasificación. Existen modelos pronósticos en algunas enfermedades como la cirrosis biliar primaria ${ }^{5}$ o la colangitis esclerosante primaria ${ }^{6}$ que permiten predecir la supervivencia de los pacientes con estas enfermedades y ayudan a indicar el momento del TH. En estas dos enfermedades, el TH puede estar indicado en casos de osteodistrofia hepática grave, prurito refractario al tratamiento o colangitis de repetición (colangitis esclerosante primaria).

La insuficiencia hepática aguda grave se define por la aparición de encefalopatía hepática en las primeras ocho semanas desde el primer síntoma de enfermedad hepática. Es una indicación poco habitual de TH. Sus principales causas son infecciones virales, agentes tóxicos (fundamentalmente paracetamol) o, más frecuentemente, desconocida. En esta enfermedad, es muy importante que el paciente sea trasladado a un centro de referencia de forma precoz. Los criterios utilizados más frecuentemente para indicar el TH son los del King's College (Tabla 2).

Tabla 2. Indicaciones de trasplante hepático en la insuficiencia hepática aguda grave. Criterios del King's College.

- Intoxicación por paracetamol (uno de los siguientes)

- $\mathrm{pH}$ arterial $<7,3$

- INR $>6,5$ + creatinina $>3,4 \mathrm{mg} / \mathrm{dL}$.

- Otras causas (uno de los siguientes)

- INR > 6,5

- Tres de los siguientes

1. Edad < 10 ó > 40 años.

2. Etiología: hepatitis noA-noB, hepatitis por halotano, reacción farmacológica idiosincrásica.

3. INR $>3,5$.

4. Bilirrubina $>17,6 \mathrm{mg} / \mathrm{dL}$.

5. Duración de ictericia antes de encefalopatía > 7 días.

El segundo gran grupo de indicaciones en importancia numérica son los tumores hepáticos. El TH se ha indicado en distintos tumores hepáticos primarios o secundarios, pero el más frecuente es el hepatocarcinoma. Este tumor afecta de forma casi exclusiva a pacientes con cirrosis hepática, lo que limita la resección hepática, incluso en los casos en que se detecten de forma precoz. Diversos estudios han comprobado que los pacientes con grandes lesiones tumorales o con lesiones multicéntricas tienen una elevada frecuencia de recidiva tumoral. Por ello, aunque los límites varían en los distintos grupos, la mayoría indica el trasplante únicamente en pacientes que tengan un hepatocarcinoma de cinco centímetros de diámetro como máximo y que no tengan más de tres lesiones tumorales ${ }^{8}$. 
El colangiocarcinoma, la segunda neoplasia hepática primitiva en orden de frecuencia, está considerada como una contraindicación para el TH por la mayoría de los grupos, porque la recidiva tumoral tras el trasplante es la norma". Sin embargo, recientemente se ha publicado una serie de once pacientes tratados con quimioterapia y radioterapia preoperatorias en la que únicamente se ha producido una recidiva ${ }^{10}$

Otros tumores en los que se acepta el TH son el hepatocarcinoma fibrolamelar, el hepatoblastoma, el hemangioendotelioma epitelioide y casos seleccionados de metástasis de tumores neuroendocrinos. Sin embargo, el TH no se considera una opción aceptable en el angiosarcoma ni en metástasis de otros tumores, porque la incidencia de recidiva es elevadísima.

Existe un grupo de enfermedades metabólicas en las que el TH puede ser una opción curativa. En algunas de ellas existe un deterioro global de la función hepática, como en la hemocromatosis, la enfermedad de Wilson y el déficit de alfa-1-antitripsina. En otros casos, el hígado es morfológica y funcionalmente normal, pero tiene un defecto enzimático que es responsable de una enfermedad sistémica, como en la polineuropatía amiloidótica familiar o en la hiperoxaluria primaria.

El retrasplante hepático es la consecuencia del fracaso de la función del injerto hepático. Se encuentra indicado en dos tipos de situaciones: urgente y electivo. El retrasplante urgente, en el postoperatorio inmediato del $\mathrm{TH}$, se realiza en el caso de fallo primario del injerto, de complicación técnica (fundamentalmente trombosis de la arteria hepática) y, excepcionalmente en el rechazo hiperagudo. El retrasplante electivo se realiza fundamentalmente en casos de rechazo crónico y de recidiva de la enfermedad de base (sobre todo en la cirrosis por virus C) y, menos frecuentemente, por consecuencias tardías de complicaciones vasculares o biliares.

Por último, existe una miscelánea de indicaciones de TH. En estas indicaciones, el número de $\mathrm{TH}$ realizados es muy escaso. Se trata de la poliquistosis hepática, hiperplasia nodular regenerativa, traumatismo hepático...

\section{Contraindicaciones}

Las contraindicaciones para el TH pueden ser absolutas o relativas (Tabla 3 ). Se consideran contraindicaciones absolutas aquellas enfermedades extrahepáticas cuyo pronóstico a corto plazo sea muy malo y/o las situaciones en las que se conoce que la supervivencia después del TH es muy mala. En algunas de ellas, sin embargo, un trasplante combinado (hígado-pulmón o hígado-corazón) puede ser un tratamiento eficaz. 
Tabla 3. Contraindicaciones para el trasplante hepático.

- Absolutas

Enfermedad extrahepática mortal a corto plazo

- SIDA

- Tumor extrahepático o metastásico

- Enfermedad neurológica grave

- Enfermedad pulmonar grave

- Enfermedad cardiaca grave

Sepsis activa

Antecedente reciente de neoplasia extrahepática

Alcoholismo o toxicomanía activos

Incapacidad psicológica

Colangiocarcinoma

Infección replicativa por virus de hepatitis $B$

Trombosis portal y mesentérica completa

- Relativas

Edad avanzada (valorar edad biológica)

Mal estado nutricional

Insuficiencia renal

Enfermedad hepática muy avanzada

Cirugia hepatobiliar previa

Trombosis portal parcial

Enfermedad cardiaca

Enfermedad pulmonar

Diabetes

Historia de patología psiquiátrica mayor

EI SIDA tiene un pronóstico muy malo a corto plazo, que probablemente empeorará con el tratamiento inmunosupresor, por lo que en principio es una contraindicación absoluta para el TH. Sin embargo, los actuales tratamientos antirretrovirales combinados se asocian a una mejoría del pronóstico de los pacientes con infección por VIH. Por ello, pese a que las primeras experiencias con el trasplante en pacientes con enfermedad por VIH fueron muy malas, se han realizado algunos trasplantes de órganos en situaciones controladas en pacientes con tratamiento antirretroviral combinado con resultados prometedores, aunque el seguimiento es aún muy breve para poder generalizar el TH en estos pacientes.

Algunas contraindicaciones absolutas, como la existencia de sepsis extrahepática activa, neoplasia extrahepática reciente, alcoholismo o toxicomanía o infección replicativa por el virus de la hepatitis B (por la elevada incidencia de recidiva de la infección en estos casos) son transitorias. Habitualmente se espera al menos 6 meses de abstinencia de alcohol antes de realizar un TH a un paciente con cirrosis etílica. Esta espera no es únicamente un criterio utilizado para estimar si el paciente mantendrá la abstinencia (y otros cuidados) tras el TH; la cirrosis etílica puede mejorar funcionalmente en los meses siguientes a la interrupción del consumo de alcohol y trasplantar a un 
paciente en ese periodo podría suponer realizar un TH innecesario. La mayoría de los tumores malignos se consideran curados 5 años después de su tratamiento. Este periodo de 5 años es el limite que se utiliza habitualmente para contraindicar el TH por tener antecedentes de neoplasia. Sin embargo, en algunos casos, la supervivencia esperable sería muy baja si se completara este plazo; por ello, el plazo puede acortarse de forma individualizada, aunque nunca a menos de dos años (salvo tumores in situ o neoplasias cutáneas) ${ }^{11}$.

Las contraindicaciones relativas se producen cuando existen condiciones que aumentan la morbilidad y mortalidad relacionadas con el $\mathrm{TH}$, aunque de forma aislada no contraindican el TH. La coexistencia de varias de estas condiciones puede incrementar el riesgo hasta el punto de suponer una contraindicación absoluta.

\section{INMUNOSUPRESIÓN}

En el TH se utilizan habitualmente cuatro grupos de fármacos inmunosupresores: inhibidores de la calcineurina (ciclosporina A y tacrolimus), fármacos que interfieren con la división celular (azatioprina y micofenolato mofetil, fundamentalmente), glucocorticoides, y anticuerpos monoclonales o humanizados frente a receptores linfocitarios (como OKT3, basiliximab o daclizumab).

La inmunosupresión se gradúa en tres niveles distintos. El tratamiento de inducción se administra en las primeras semanas después del TH; en esta fase habitualmente se combinan un inhibidor de la calcineurina, azatioprina y dosis relativamente altas de glucocorticoides, aunque algunos grupos también utilizan inmunosupresores más potentes como los anticuerpos antilinfocitarios. El segundo nivel es el del tratamiento del rechazo agudo; en estos casos suelen utilizarse altas dosis de fármacos inmunosupresores durante un periodo breve (megadosis de metilprednisolona u OKT3), aunque en algunos episodios de rechazo leve puede bastar con incrementos moderados de la inmunosupresión. Por último, para la inmunosupresión de mantenimiento se intenta utilizar las mínimas dosis de los fármacos inmunosupresores de forma que se limiten los efectos secundarios de su uso. A largo plazo, más del $80 \%$ de los receptores de un TH se encuentran en monoterapia imunosupresora con un inhibidor de la calcineurina a dosis bajas.

\section{RESULTADOS}

\section{Supervivencia}

Las tres cuartas partes de la mortalidad tras el trasplante hepático se localizan en el primer año después del mismo ${ }^{12}$. 
Esto se debe a que en estos primeros meses se producen, además de las complicaciones propias de una cirugía mayor, la mayoría de los episodios de rechazo, así como las principales complicaciones infecciosas y neoplásicas, consecuencia del tratamiento inmunosupresor.

Las principales causas de mortalidad durante el primer año tras el TH son las complicaciones infecciosas (facilitadas en parte por el estado general del paciente previo al trasplante y por el aumento del tratamiento inmunosupresor en los pacientes con rechazo agudo), otras complicaciones del postoperatorio inmediato, recidiva tumoral (en los pacientes trasplantados por tumores hepáticos) y linfomas. Después del primer año, las principales causas de mortalidad son la recidiva de la enfermedad de base (sobre todo en pacientes trasplantados por cirrosis de origen viral), complicaciones cardiovasculares (consecuencia de las complicaciones metabólicas habituales tras el trasplante), infecciones y otras neoplasias.

Tanto en el registro español (periodo 1984-98) ${ }^{13}$ como en el europeo $(1988-97)^{12}$ o en el estadounidense $(1992-94)^{14}$, la supervivencia al cabo de un año del TH se encuentra entre el 75 y el $80 \%$, mientras que la supervivencia a 5 años en el registro español y en el registro europeo es del $66 \%$. Estos resultados van mejorando progresivamente; de forma que en el registro español la supervivencia a un año ha aumentado del $51 \%$ en el periodo $1984-87$, al $68 \%$ en el $1988-90$, siendo el $77 \%$ en el 1991-93, del 80\% en el 1994-96 y del $82 \%$ en el $1997-98$.

No todos los pacientes tienen igual supervivencia tras un TH. Los principales factores de riesgo de mortalidad tras el TH son: retrasplante, indicación del TH por insuficiencia hepática aguda grave o por tumor o que la actividad del centro donde se realiza el trasplante sea escasa.

\section{Calidad de vida}

Tras el TH se produce una resolución completa de las alteraciones secundarias a la enfermedad hepática, tales como la astenia, el prurito de las enfermedades colestáticas, la retención hidrosalina en forma de edemas, ascitis o derrame pleural, alteraciones sexuales, estado nutricional... Ello permite la reintegración a una vida normal en el $80 \%$ de los pacientes, incluyendo la posibilidad de reiniciar su actividad laboral.

Existe, no obstante una serie de limitaciones mínimas en la vida cotidiana, que habitualmente no suponen un trastorno importante en la calidad de vida. Además, los pacientes deben mantener un tratamiento farmacológico de forma indefinida y deben acudir a revisiones médicas con cierta frecuencia. Por último, existe un buen número de enfermedades asociadas al trasplante, habitualmente efectos secundarios del tratamiento inmunosupresor, que obligan a realizar un tratamiento far- 
macológico y, en un pequeño porcentaje de pacientes, provocan alteraciones en su calidad de vida.

\section{COMPLICACIONES DEL TRASPLANTE HEPÁTICO}

\section{Complicaciones del injerto}

La primera complicación que puede aparecer tras el TH es la disfunción primaria del injerto. Habitualmente es la consecuencia de una mala preservación del órgano, de una isquemia prolongada, de esteatosis hepática masiva o de hipernatremia severa en el donante. Puede provocar un cuadro similar al de la insuficiencia hepática aguda grave y, cuando es de gravedad suficiente, puede ser una indicación de retrasplante.

La complicación más característica tras el TH es el rechazo del injerto. El rechazo hiperagudo, que es excepcional tras el TH, incluso aunque el crossmatch sea positivo, está causado por anticuerpos preformados por el receptor y produce un cuadro en el postoperatorio inmediato muy similar al de la disfunción primaria del injerto.

El rechazo agudo es la consecuencia de la respuesta inmune celular del receptor frente a antígenos del donante, fundamentalmente frente a antígenos HLA de clase II, expresados en las células del epitelio biliar y en el endotelio vascular. Se produce en un $25-35 \%$ de los TH y habitualmente sucede en las primeras semanas tras el TH, con un pico de aparición al final de la primera semana, aunque pueden producirse episodios de rechazo agudo tardíos, sobre todo si el tratamiento inmunosupresor no se sigue de forma adecuada. Habitualmente, los episodios de rechazo agudo son asintomáticos, aunque en ocasiones se produce fiebre, o malestar general. El tratamiento del rechazo agudo es satisfactorio en más del $95 \%$ de los casos, pero el incremento de la inmunosupresión utilizado para el tratamiento del rechazo puede favorecer el desarrollo de infecciones oportunistas o de otras complicaciones del tratamiento inmunosupresor.

El rechazo crónico es habitualmente la consecuencia de un rechazo agudo no controlado. Histológicamente se caracteriza por una arteritis de células espumosas y una ductopenia y clínicamente, por un cuadro de colestasis progresiva, con ictericia, prurito, esteatorrea... Con los regímenes inmunosupresores usados en la actualidad, su incidencia es menor de $5 \%$. La respuesta al tratamiento, con tacrolimus o micofenolato mofetil, es variable, según su gravedad, por lo que en la mitad de los casos es preciso el retrasplante.

Entre las complicaciones técnicas, la que tiene habitualmente una evolución más dramática es la trombosis de la arteria hepática, que puede causar un cuadro similar al de la disfunción primaria del injerto, sobre todo si se produce en el 
postoperatorio inmediato. En fases más tardías suele producir una colangiopatía isquémica, similar a la colangitis esclerosante primaria, en la que se producen múltiples estenosis y dilataciones en la vía biliar, que pueden ser la base para que se produzcan episodios de colangitis infecciosa y abscesos intrahepáticos.

La trombosis portal es más frecuente en pacientes con trombosis portal previa al trasplante. Habitualmente, su repercusión sobre la función del injerto es escasa y se manifiesta por complicaciones de la hipertensión portal, como hemorragia digestiva varicosa. La trombectomía quirúrgica, la fibrinolisis del trombo portal o el tratamiento de la hipertensión portal son las opciones terapéuticas en estos pacientes.

La trombosis o estenosis de la vena cava inferior (habitualmente en su anastomosis suprahepática) produce una congestión del injerto que se manifiesta clínicamente por ascitis. El tratamiento puede ser quirúrgico o percutáneo (dilatación de la zona estenótica o colocación de endoprótesis vasculares).

Entre las complicaciones biliares, las más frecuentes son las fístulas biliares anastomóticas (facilitadas por la hipertonía de denervación que se produce en el esfínter de Oddi) o las que se producen tras la retirada del drenaje biliar externo. En la mayor parte de ellas el tratamiento es conservador. Se pueden producir estenosis de la vía biliar por retracción de la anastomosis quirúrgica, como consecuencia de colangiopatía isquémica o por compresión de la vía biliar.

La recidiva de la enfermedad causante por la que se ha realizado el TH es particularmente frecuente en las hepatopatías de causa viral. En los pacientes trasplantados por cirrosis hepática por virus $\mathrm{C}$, la infección se encuentra prácticamente siempre en estado de replicación viral activa. Por ello, en estos pacientes la infección por el virus $\mathrm{C}$ persiste en todos los casos, aumentando la replicación viral por el tratamiento inmunosupresor. Como consecuencia, la recidiva de la hepatitis C tras el TH es muy frecuente (por encima del $50 \%$ en todas las series) ${ }^{15}$. En la mayoría de estos pacientes se produce una hepatitis crónica, en ocasiones con rápida evolución a la cirrosis, aunque en muchos casos es una enfermedad poco activa. En menos del 10\% de los casos, se produce una forma de recidiva de la hepatitis $C$ en la que se desarrolla una colestasis progresiva que lleva al fallo del injerto en pocos meses ${ }^{16}$. El retrasplante en estos pacientes en los que la hepatitis C lleva a un fracaso del injerto se sigue frecuentemente de una mala evolución, por lo que muchos grupos lo contraindican.

En los pacientes con cirrosis hepática por virus $\mathrm{B}$ que se trasplantan en fase de replicación viral activa (DNA de virus B detectable en suero), la recidiva es prácticamente la norma; 
por ello, en estos pacientes se contraindica el TH. Tras el TH por una hepatopatía causada por el virus $B$, se administra inmunoglobulina hiperinmune frente al virus $B$ y/o lamivudina para reducir el riesgo de recidiva de la hepatitis $B$ en el injerto. El riesgo de esta recidiva, usando tratamiento profiláctico, varía según la enfermedad de base, siendo mayor en los pacientes trasplantados por cirrosis por virus B que en los pacientes trasplantados por cirrosis hepática por coinfección por los virus B y delta o por insuficiencia hepática aguda grave. La reinfección por el virus $\mathrm{B}$ tras el $\mathrm{TH}$ produce frecuentemente insuficiencia hepática aguda grave, hepatitis crónica activa con rápida evolución a la cirrosis o hepatitis colestásica fibrosante (una forma de infección por el virus B característica de pacientes inmunosuprimidos, en los que existe una colestasis progresiva, con mínimas citolisis y actividad inflamatoria, que tiene muy mal pronóstico $)^{17}$. Otra posible fuente de hepatitis B en los pacientes trasplantados es el hígado donante. Los receptores de injertos hepáticos procedentes de donantes con marcadores serológicos de hepatitis B pasada (antígeno de superficie negativo, anticuerpos frente al antígeno del core del virus $\mathrm{B}$ positivos) tienen una incidencia superior al $50 \%$ de hepatitis $\mathrm{B}^{18}$. Afortunadamente, estas hepatitis B de novo son en la mayoría de los casos de curso más benigno que la recidiva de la hepatitis $B$.

También se ha documentado la recidiva de otras enfermedades hepáticas tras el TH, como la cirrosis biliar primaria, la colangitis esclerosante primaria o la hepatitis crónica autoinmune. En todas ellas es muy infrecuente la evolución hacia una hepatopatía crónica avanzada.

La recidiva del hábito etílico en pacientes trasplantados por cirrosis alcohólica, provoca nuevamente daño hepático y puede ser causa de problemas en el seguimiento del tratamiento.

Por último, puede producirse la recidiva tumoral en los pacientes trasplantados por tumores malignos, fundamentalmente en pacientes con hepatocarcinoma. Los órganos afectados más frecuentemente son el nuevo hígado y los pulmones. La incidencia de recidiva tumoral está directamente relacionada con el tamaño y el número de lesiones que presenta el paciente.

\section{Complicaciones extrahepáticas}

Las complicaciones extrahepáticas tras el TH pueden clasificarse en dos tipos, las de causa inmunológica, secundarias al tratamiento inmunosupresor utilizado para evitar o tratar el rechazo del injerto y las de causa no inmunológica, relacionadas con el propio acto quirúrgico o con la toxicidad no inmunológica de los fármacos inmunosupresores. 
Entre las complicaciones inmunológicas, las infecciones suponen la primera causa de muerte tras el TH. Habitualmente, se establecen tres periodos, en los cuales el riesgo de complicaciones infecciosas es distinto ${ }^{19}$. Durante el primer mes, las principales complicaciones infecciosas son las habituales tras una cirugía hepatobiliar (neumonía, infecciones urinarias, de la herida quirúrgica, colangitis...), aunque agravadas por el tratamiento inmunosupresor. El uso de descontaminación intestinal desde el periodo preoperatorio, con fármacos que reduzcan la población de bacilos gramnegativos y de hongos en el tubo digestivo se asocia a una reducción del riesgo de infecciones durante este periodo. Los principales factores de riesgo para que se produzcan infecciones durante este periodo son el estado general previo al TH y las complicaciones intraoperatorias y postoperatorias inmediatas. A partir del final del primer mes y hasta el final del primer semestre posttrasplante, se producen sobre todo infecciones oportunistas, como consecuencia de la inmunosupresión (infecciones por citomegalovirus, fúngicas...), por lo que el principal factor de riesgo para estas infecciones es haber sufrido un episodio de rechazo agudo, tratado con dosis altas de metilprednisolona u OKT3 (un anticuerpo monoclonal dirigido frente al receptor CD3 de los linfocitos T activados). Los pacientes con serología negativa para citomegalovirus que reciben un injerto de una persona con serología positiva para dicho virus tienen un alto riesgo de sufrir una infección por citomegalovirus. A partir del sexto mes postoperatorio, no son frecuentes las infecciones oportunistas, salvo en pacientes que tengan rechazo del injerto y requieran dosis más elevadas de fármacos inmunosupresores, sin embargo, estos pacientes sí tienen un riesgo de presentar infecciones de la comunidad algo superior a la población general.

Al menos un 10-15\% de los receptores de un TH desarrollan neoplasias tras el $\mathrm{TH}^{20}$. Los tumores más frecuentes son los cutáneos, tanto basocelulares como espinocelulares, en relación con la radiación solar, de forma que en países con elevada radiación, como Australia, el riesgo de cáncer de piel es mayor de $50 \%$ al cabo de 15 años tras un trasplante renal. El sarcoma de Kaposi se produce en menos del $1 \%$ de los pacientes trasplantados, pero, puesto que este tumor es excepcional en personas inmunocompetentes, el riesgo relativo de sarcoma de Kaposi tras el TH es 100 veces superior al de la población general ${ }^{21}$.

Entre un 1 y un $5 \%$ de los pacientes trasplantados desarrollan un linfoma. Estos linfomas son la consecuencia de una proliferación de linfocitos B infectados por el virus de EpsteinBarr. El uso de OKT3 multiplica el riesgo de desarrolar un linfoma ${ }^{22}$. Cuando esta proliferación linfocitaria no es aún monoclonal, puede regresar con una importante reducción del 
tratamiento inmunosupresor y aciclovir. Sin embargo, en los linfomas completamente establecidos el tratamiento debe ser quimioterápico.

La incidencia de otros tumores en los pacientes trasplantados es menor, aunque cabe destacar el riesgo de tumores de cabeza y cuello que presentan los pacientes fumadores.

Entre las complicaciones no inmunes, son muy frecuentes la insuficiencia renal y la hipertensión arterial, causadas por los inmunosupresores más frecuentemente utilizados ciclosporina A y tacrolimus. El mecanismo fundamental de esta toxicidad es una inhibición en la síntesis de prostaglandinas renales causada por ambos fármacos. Es muy infrecuente que la nefrotoxicidad de estos fármacos lleve a una insuficiencia renal terminal, pero en los casos de asociación de nefropatía y hepatopatía (como cirrosis por virus $\mathrm{C}$ y glomerulonefritis membranoproliferativa o cirrosis etílica y glomerulonefritis mesangial) esta nefropatía puede empeorar como consecuencia de estos fármacos nefrotóxicos. La ciclosporina y el tacrolimus también disminuyen la excreción renal de ácido úrico, por lo que aproximadamente el $50 \%$ de los pacientes desarroIlan hiperuricemia, aunque ésta es sintomática únicamente en un $10-15 \%$ de los casos.

Tras el TH se producen diversas complicaciones metabólicas, como obesidad (aproximadamente en el 30\% de los pacientes), hipercolesterolemia (25\%), diabetes (15\%). Todo ello, junto con la hipertensión arterial, que se produce en más del $50 \%$ de los pacientes tratados con ciclosporina (la incidencia de hipertensión en pacientes tratados con tacrolimus es de 25-35\%), hace que el riesgo cardiovascular de los pacientes trasplantados sea importante, por lo que estas complicaciones son una de las principales causas de mortalidad tardía en los pacientes trasplantados.

Existen otras posibles complicaciones, como osteoporosis, afectación neurológica o psiquiátrica, cuya incidencia es menor.

\section{EL TRASPLANTE HEPÁTICO EN NAVARRA}

La actividad de TH en Navarra comenzó en abril de 1990. Desde entonces hasta finales de agosto de 2000 , se han realizado un total de 180 TH a 174 pacientes (6 fueron retrasplantes). Las características generales de los pacientes trasplantados en este periodo se muestran en la tabla 4. En la figura 1 se muestra el número de $\mathrm{TH}$ realizados cada año; como puede verse, este número anual ha sido relativamente constante, salvo en 1990 en que únicamente se realizaron $4 \mathrm{TH}$. Como se muestra en la figura 2, las dos principales indicaciones fueron cirrosis etílica y cirrosis hepática por virus C. Cincuenta y cinco pacientes (32\%) tenían hepatocarcinoma, todos ellos 
Tabla 4. Características generales de los receptores de trasplante hepático en Navarra (Abril-1990 a Agosto-2000).

\begin{tabular}{ccc}
\hline Edad (años) & $55,22 \pm 0,79$ (rango: $8-73)$ \\
Menores de 60 años & $108(62 \%)$ \\
60-64 años & $30(17 \%)$ \\
65 años o mayores & $36(21 \%)$ \\
Sexo & Varones & $127(73 \%)$ \\
Mujeres & & $47(27 \%)$ \\
Estadio Child-Pugh & $\mathrm{A}$ & $20(12 \%)$ \\
& $\mathrm{B}$ & $84(50 \%)$ \\
& $\mathrm{C}$ & $65(38 \%)$ \\
\hline
\end{tabular}

Probabilidad de supervivencia (\%)

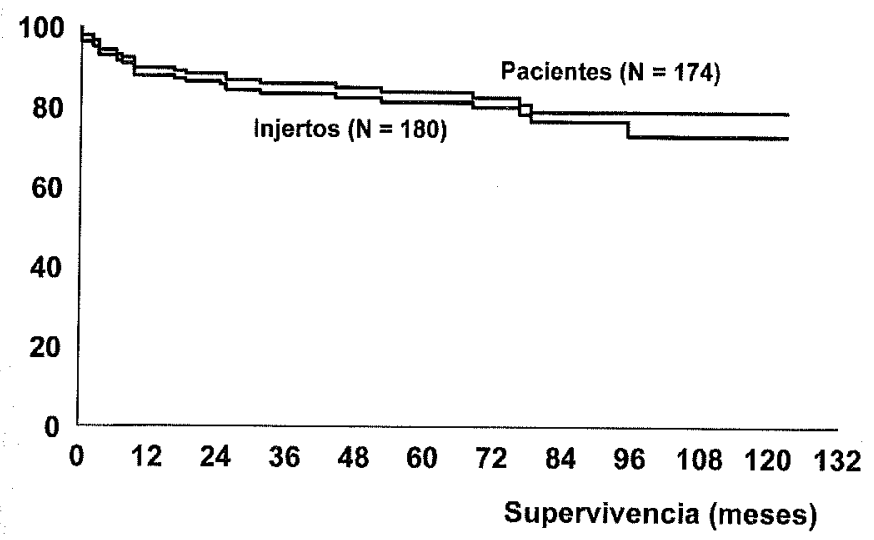

Figura 1. Supervivencia actuarial de pacientes e injertos en los 180 trasplantes hepáticos realizados en Navarra desde Abril de 1990 hasta Agosto de 2000.

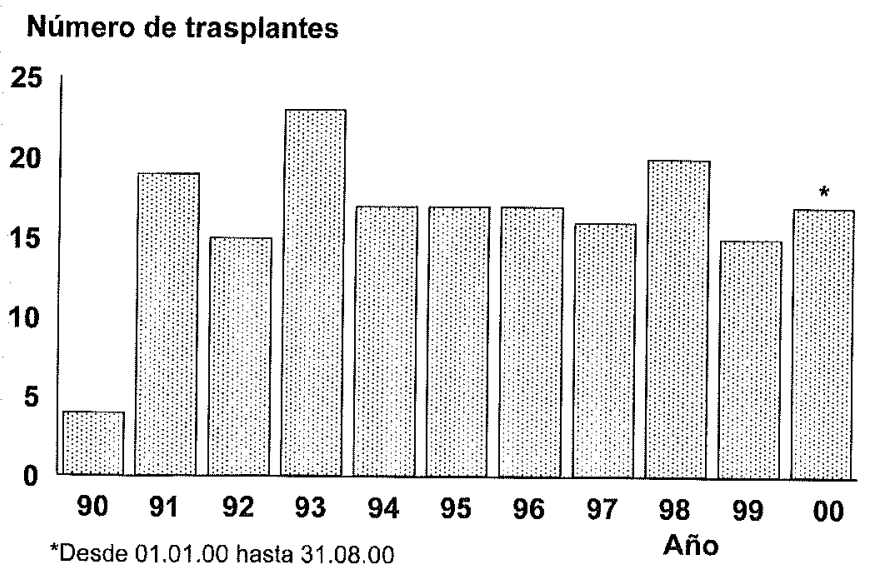

Figura 2. Número de trasplantes hepáticos realizados en Navarra cada año. 
sobre un hígado con cirrosis, 32 por virus $\mathrm{C}, 13$ de causa etílica, 4 por virus B, 3 por hemocromatosis, 2 por cirrosis biliar primaria y uno por cirrosis criptogenética. La incidencia de hepatocarcinoma en pacientes trasplantados por cirrosis de causa viral fue del $51 \%$, mientras que en las cirrosis de otras etiologías, únicamente el $19 \%$ de los pacientes tenía hepatocarcinoma.

Durante el seguimiento (mediana: 44 meses), han fallecido 27 pacientes. La supervivencia de pacientes e injertos se muestra en la figura 3 . A fin de conocer qué factores pueden influir sobre la supervivencia de los pacientes tras el trasplante, se ha analizado la posible influencia sobre la misma de los siguientes factores: edad, sexo, etiología de la cirrosis (viral versus no viral), estadio funcional de Child-Pugh, patología tumoral hepática, origen del donante y del receptor (Navarra versus otras) y año del trasplante (periodo 1990-96 versus 1997-2000). En el estudio univariado, dos factores se asociaron a una mejor supervivencia: menor edad y haber sido trasplantado en el periodo 1997-2000. En el análisis multivariado, únicamente una mayor edad se asoció de forma independiente a una menor supervivencia.

\section{PERSPECTIVAS DE FUTURO}

Existen dos líneas principales de investigación actual en el TH: la obtención de estrategias de inmunosupresión más eficaces y seguras y el incremento en el número de trasplantes.

Los tratamientos inmunosupresores que se utilizan en la actualidad han conseguido que la incidencia de rechazos tras el TH sea muy baja y que la pérdida de injertos por causa inmune sea prácticamente nula. Sin embargo, el tratamiento

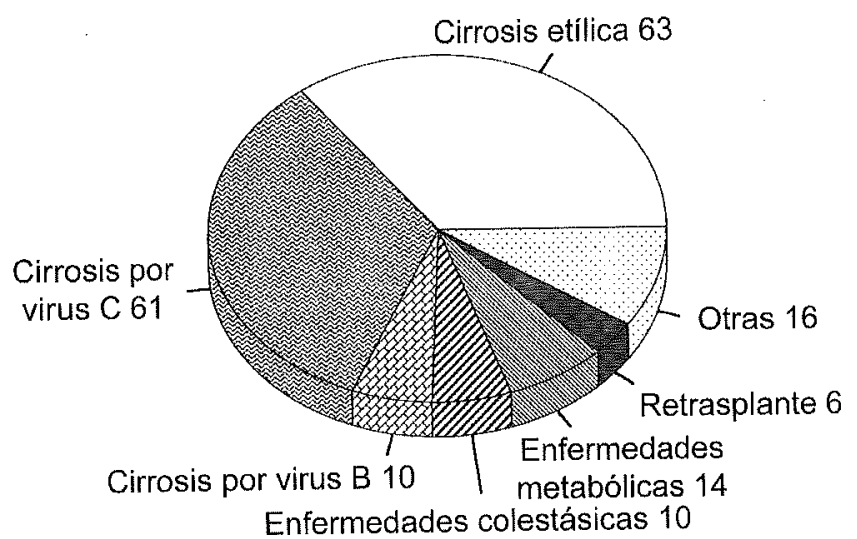

Figura 3. Indicaciones de trasplante hepático en los 180 trasplantes hepáticos realizados en Navarra desde Abril de 1990 hasta Agosto de 2000. 
inmunosupresor actual tiene dos inconvenientes fundamentales: habitualmente debe mantenerse de forma indefinida y tiene unos efectos secundarios (inmunes y no inmunes) con repercusiones potenciales sobre la calidad de vida y el pronóstico de los pacientes. El desarrollo de nuevos fármacos inmunosupresores ha supuesto una importante mejoría en el manejo de los pacientes con toxicidad farmacológica de causa no inmune: el uso de micofenolato mofetil ha permitido reducir las dosis de ciclosporina A o tacrolimus de los pacientes con nefrotoxicidad, hipertensión arterial de difícil control o neurotoxicidad por estos fármacos, con la consiguiente mejoría de estos efectos secundarios ${ }^{23}$. En los pacientes con insuficiencia renal antes del trasplante, en los que los fármacos nefrotóxicos deben evitarse en la medida de lo posible, se han usado estrategias en las que se reduce la dosis de ciclosporina A o tacrolimus y se administran fármacos no nefrotóxicos como micofenolato mofetil y los nuevos anticuerpos frente al receptor de la interleuquina-2, daclizumab y basiliximab ${ }^{24}$. Sin embargo, la situación inmunológica ideal es la tolerancia entre donante y receptor. Esta situación se alcanza a largo plazo en algunos casos, pero se desconoce en qué casos puede llegar a abandonarse la inmunosupresión, y la interrupción de este tratamiento, incluso aunque se realice de forma paulatina, se asocia a un riesgo de rechazo y pérdida del injerto. En este sentido, las nuevas técnicas de terapia génica, que pueden permitir realizar modificaciones antigénicas en el donante o en el receptor, abren un campo de esperanza para alcanzar esta tolerancia.

A pesar del incremento ininterrumpido del número de $\mathrm{TH}$ realizados tanto en España como en otros países, el número de pacientes en lista de espera aumenta cada año y, en consecuencia, también aumenta el tiempo transcurrido en lista de espera para TH y el número de pacientes que fallecen sin llegar a ser trasplantados. Para poder aumentar el número de donantes, se han utilizado injertos procedentes de donantes que hace pocos años se consideraban inaceptables. En este sentido, aunque hace pocos años se establecía el límite de edad de un donante hepático en 50 años, en la actualidad se usan con éxito donantes de más de 80 años $^{25}$. No obstante, los órganos procedentes de donantes de mayor edad son más sensibles a la isquemia prolongada y algunos estudios han encontrado que la edad de los donantes es un factor de riesgo de mortali$\mathrm{dad}^{26}$. Por ello, el número potencial de donantes utilizables de esta forma es bastante limitado. Otras estrategias para aumentar el número de donantes válidos son la extracción de órganos a donantes en paro cardiaco y el trasplante de órganos de donantes con hepatitis C (sin fibrosis hepática) a receptores con cirrosis por virus C. De esta manera, el aumento de potenciales donantes continúa siendo muy limitado. 
La división del hígado donante (trasplante hepático split), mediante la cual, de un mismo hígado se obtienen injertos para dos receptores (habitualmente uno de ellos de edad pediátrica o de bajo peso) puede permitir aumentar el número de injertos válidos. El procedimiento es técnicamente complejo y requiere la coordinación de dos equipos quirúrgicos, por lo que aún no se utiliza frecuentemente ${ }^{27}$.

Recientemente ha sufrido un gran auge un procedimiento para aumentar el número de TH: el trasplante a partir de un donante vivo. Esta técnica comenzó a utilizarse en TH pediátrico, utilizándose como injerto el lóbulo hepático izquierdo. En algunos países como Japón, en que no hay donaciones de cadáver por motivos religioso-culturales, esta es la única fuente de injertos para TH. Para poder hacer posible el TH a los adultos, se ha desarrollado la técnica de donación del lóbulo hepático derecho, que supone aproximadamente el $60 \%$ de la masa hepática ${ }^{28}$. La experiencia acumulada hasta la fecha ha sido positiva, la incidencia de complicaciones en el donante es aceptable y la mortalidad de los donantes prácticamente nula, aunque se ha documentado un fallecimiento por cada 1.000 donaciones.

El xenotrasplante (el trasplante de un órgano de otra especie animal al hombre) es teóricamente la solución idónea para el problema de la escasez de órganos para trasplante. A pesar de que un gran número de investigadores trabajan en este campo, aún no se ha conseguido el control de la respuesta inmune, ya que, además de la respuesta inmune celular que protagoniza el rechazo del alotrasplante, en el rechazo de los xenoinjertos participa de forma importante la respuesta inmune humoral. Por otro lado, hay que tener en cuenta el problema adicional que supone que la gran cantidad de proteínas sintetizadas y secretadas por el hígado sean de otra especie.

\section{CONCLUSIONES}

El TH es un procedimiento terapéutico cuyos resultados, en términos de supervivencia, han mejorado progresivamente. En la actualidad, la supervivencia al año del trasplante se encuentra en torno al $90 \%$. La mejoría en la inmunosupresión y en el tratamiento de las complicaciones posteriores al TH ha contribuido de forma decisiva a esta mejoría en los resultados. Sin embargo, el tratamiento inmunosupresor que se usa en la actualidad se asocia a una serie de efectos secundarios. En el futuro debe disponerse de fármacos inmunosupresores de menor toxicidad.

La limitación en el número de potenciales donantes de órganos hace que el $\mathrm{TH}$ no pueda utilizarse en todos los pacientes con enfermedades hepáticas que podrían beneficiarse de este tratamiento. Para poder aumentar el número de 
potenciales beneficiarios del TH se trabaja en el TH split, en la obtención de injertos hepáticos a partir de donantes vivos y en el xenotrasplante.

\section{BIBLIOGRAFÍA}

1. Starzl te, marchioro Tl, Von Kaulla kn, Hermann G, Britain RS, Waddell WR. Homotransplantation of the liver in humans. Surg Gynecol Obstet 1963; 117: 659-676.

2. National Institutes of Health. Consensus Development Conference Statement: Liver Transplantation; June 20-23, 1983. Hepatology 1983; 4: 107S-110S.

3. Fuente: Organización Nacional de Trasplantes. www.msc.es/ont/esp/estadisticas/f_estadisticas.htm

4. Ginés P, Quintero E, Arroyo V, Terés J, Bruguera M, Rimola A et al. Compensated cirrhosis: natural history and prognostic factors. Hepatology 1987; 7: 122-128.

5. Dickson ER, Grumbsch PM, FLEming TR, Fisher LD, LANGworthy A. Prognosis in primary biliary cirrhosis: a model for decision making. Hepatology 1989; 10: 1-7.

6. Dickson ER, Murtaugh PA, Wiesner RH, Girumbsch PM, Fleming TR, LudWig J et al. Primary sclerosing cholangitis: refinement and validation of survival models. Gastroenterology 1992; 103: 1893-1901.

7. O'Grady JG, AleXander GJM, HaYLAR KH, Williams R. Early indicators of prognosis in fulminant hepatic failure. Gastroenterology 1989; 97 : 439445.

8. MOR E, KASPA RT, SHEInER P, SCwARTZ M. Treatment of hepatocellular carcinoma associated with cirrhosis in the era of liver transplantation. Ann Intern Med 1998; 129: 643-653.

9. Goldstein RM, Stone M, Tillery W, Senzer N, Levy M, Husberg Bs et al. Is liver transplantation indicated for cholangiocarcinoma? Am J Surg 1993; 166: $768-772$.

10. De Vreede I, Steers JL, Burch PA, Rosen CB, Gunderson LL, Haddock MG et al. Prolonged disease-free survival after orthotopic liver transplantation plus adjuvant chemoirradiation for cholangiocarcinoma. Liver Transpl 2000; 6: 309-316.

11. PEEN I. The effect of immunosuppression on pre-existing cancers. Transplantation 1993; 55: 742-747.

12. Adam R, Cailliez V, Ma.jno P, Karam V, McMaster P, Calne RY et al. Normalised intrinsic mortality risk in liver transplantation: European Liver Transplant Registry Study. Lancet 2000; 356: 621-627.

13. Fuente: Registro Español de Trasplante Hepático: www.msc.es/ont/esp/registro.

14. Edwards EB, Roberts JP, McBride MA, Schulak JA, Hunsicker LG. The effect of the volume of procedures at transplantation centers on mortality after liver transplantation. N Engl J Med 1999; 341: 2049-2053.

15. Herrero Ji, de la Peña A, Quiroga J, Sangro B, García N, Sola I et al. Risk factors for recurrence of hepatitis $\mathrm{C}$ after liver transplantation. Liver Transpl Surg 1998; 4: 265-270.

16. Schluger LK, Sheiner P, Thung SN, Lau JYN, Min A, Wolf DC et al. Severe recurrent cholestatic hepatitis $\mathrm{C}$ following orthotopic liver transplantation. Hepatology 1996; 23: 971-976.

17. Davies SE, Portmann BC, O’Grady JG, Aldis PM, Chaggar K, Alexander GJM et al. Hepatical histological findings after transplantation for chronic 
hepatitis B virus infection, including a unique pattern of fibrosing cholestatic hepatitis. Hepatology 1991; 13: 150-157.

18. Dickson RC, Everhart JE, Lake JR, Wei Y, SEaberg EC, Wiesner RH et al Transmission of hepatitis B by transplantation of livers form donors positive for antibody to hepatitis B core antigen. The National Institutes of Diabetes and Digestive and Kidney Diseases Liver Transplantation Database. Gastroenterology 1997; 113: 1668-1674.

19. RUBIN RH. Infectious disease problems. En: Maddrey WC, Sorrell MF, editores. Transplantation of the liver, second edition. Norwalk: Appleton \& Lange, 1995: 367-398.

20. Galvé ML, Cuervas-Mons V, Figueras J, Herrero Ji, Mata M, Clemente G et al. Incidence and outcome of de novo malignancies after liver transplantation. Transplant Proc 1999; 31: 1275-1277.

21. OTLEY CC, PITTELKOW MR. Skin cancer in liver transplant recipients. Liver Transpl 2000; 6: 253-262.

22. Swinnen LJ, Constanzo-Nordin MR, Fisher SG, O'Sullivan EJ, Johnson MR, HERAUX AL et al. Increased incidence of lymphoproliferative disorder after immunosuppression with the monoclonal antibody OKT3 in cardiac transplant recipients. N Engl J Med 1990; 323: 1723-1728.

23. Herrero JI, Quiroga J, Sangro B, Girala M, Gómez-Manero N, Pardo F et al. Conversion of liver transplant recipients on cyclosporine with renal impairment to mycophenolate mofetil. Liver Transpl Surg 1999; 5: 414420 .

24. Hirose R, Roberts JP, Quan D, Osorio RW, Freise C, Ascher NL et al. Experience with daclizumab in liver transplantation. Renal transplant dosing without calcineurin inhibitors is insufficient to prevent acute rejection in liver transplantation. Transplantation 2000; 307-311.

25. Jiménez C, Moreno E, Colina F, Palma F, Loinaz C, Rodríguez $\mathrm{F}$ et al. Use of octogenarian livers safely expands the donor pool. Transplantation 1999; 68: $572-575$.

26. Gayowski T, Marino IR, Singh N, Doyle H, Wagener M, Fung JJ et al. Orthotopic liver transplantation in high-risk patients: risk factors associated with mortality and infectious morbidity. Transplantation 1998; 65: 499-504

27. AZOUlay D, Hargreaves GM, Bismuth H. Impact of surgery on liver transplantation. Curr Opin Organ Transplant 2000; 5: 57-63.

28. Marcos A, Fisher Ra, Ham JM, Shifrman ML, Sanyal AJ, Luketic VAC et al Right lobe living donor liver transplantation. Transplantation 1999; 68: 798-803. 